Vol. 2 No. 2 (Desember 2021), Hal : 143-148

\title{
Sharing Knowledge and Build a Better Mindset di SMK Widya Nusantara
}

\author{
Eko Prastio ${ }^{1^{*}}$, Nugroho Marsiyanto ${ }^{2}$, Edy Susanto ${ }^{3}$ \\ 1,2,3Teknik Perminyakan, Fakultas Teknik, Universitas Bhayangkara Jakarta \\ Raya, JI. Perjuangan Raya, Marga Mulya, Bekasi Utara, Jawa Barat, 17143. Telp/fax. \\ (021) 88955871, eko.prastio@dsn.ubharajaya.ac.id, \\ nugroho.marsiyanto@dsn.ubharajaya.ac.id, edy.soesanto@dsn.ubharajaya.ac.id
}

*Korespondensi : eko.prastio@dsn.ubharajaya.ac.id

Diterima: 7 Desember 2021 ; Review: 11 Desember 2021 ; Disetujui: 26 Desember 2021 ; Diterbitkan: 31 Desember 2021

\begin{abstract}
Knowledge sharing aims to spread knowledge or information. Usually this can be in the form of activities, discussions, presentations, tutors, and many others. With the right implementation, knowledge sharing can be done well so that everyone can feel the benefits, develop and learn from each other. Knowledge sharing that can be done in increasing the potential and competence of students, can use various other ways, one of which is by making students more obedient in terms of rules at school. Having broad insight is very important for all of us. Therefore, this millennial generation must have broad insight and think better. Students as one of the components in this matter, are required to be the party that bridges the gap. In other words, the real thing that must be done by students is to help students to be able to develop for the better. Students become the driving force of change in this country who will hold the leadership relay in the future, therefore students must play an active role in being the pioneers of forming a sense of leadership. For this reason, knowledge and abilities are needed. Besides that, the development of abilities in students is very important so that they can give birth to a good next generation.
\end{abstract}

Keywords : Abdimas, build better mind

\begin{abstract}
Abstrak
Knowledge sharing bertujuan untuk menyebarkan ilmu atau informasi. Biasanya hal ini bisa berwujud dalam bentuk kegiatan, diskusi, presentasi, tutor, dan masih banyak lagi lainnya. Dengan implementasi yang tepat knowledge sharing bisa dilakukan dengan baik agar setiap orang tersebut bisa merasakan manfaatnya, saling berkembang dan belajar dari satu sama lain. Knowledge sharing yang bisa dilakukan dalam peningkatan potensi dan kompetensi siswa, bisa menggunakan berbagai cara lain, salah satunya adalah dengan membuat siswa lebih taat dalam hal peraturan disekolah. Memiliki wawasan yang luas itu sangat penting bagi kita semua. Oleh karena itu, untuk generasi milenial ini harus memiliki wawasan yang luas dan berpikir secara lebih baik. Mahasiswa sebagai salah satu komponen dalam hal ini, dituntut untuk menjadi pihak yang menjembatani kesenjangan hal tersebut. Dengan kata lain, wujud nyata yang harus dilakukan oleh mahasiswa adalah membantu siswa-siswi untuk bisa berkembang menjadi lebih baik. Mahasiswa menjadi generasi penggerak perubahan di negeri ini yang akan memegang estafet kepemimpinan di masa yang akan datang, maka dari itu mahasiswa harus berperan aktif menjadi pelopor terbentuknya rasa jiwa kepemimpinan. Untuk itu
\end{abstract}


dibutuhkan pengetahuan dan kemampuan. Selain itu pengembangan kemampuan pada siswa/siswi sangatlah penting agar bisa melahirkan generasi penerus yang baik.

\section{Kata kunci : Abdimas, build better mind}

\section{PENDAHULUAN}

Dengan mulai berkembangnya wilayah-wilayah di Kota Bekasi pada masa pemerintahan orde baru, maka pembentukan Kecamatan Rawalumbu adalah bagian dari Kecamatan Bekasi Timur, namun seiring dengan berlakunya UU Nomor 22 Tahun 1999 Tentang Otonomi Daerah, pada perkembangannya kini sesuai dengan Perda Nomor 4 Tahun 2004, Kota Bekasi mempunyai 12 kecamatan, yang terdiri dari 56 kelurahan, yaitu Kecamatan Bekasi Barat, Kecamatan Bekasi Selatan, Kecamatan Bekasi Timur, Kecamatan Bekasi Utara, Kecamatan Pondok Gede, Kecamatan Jati Asih, Kecamatan Bantar Gebang, Kecamatan Jati Sampurna, Kecamatan Medan Satria, Kecamatan Rawalumbu, Kecamatan Mustika Jaya dan Kecamatan Pondok Melati.

Kecamatan Rawa Lumbu mencakup beberapa wilayah kelurahan yaitu kelurahan Bojong Rawa Lumbu, Kelurahan Pengasinan, Kelurahan Bojong Menteng, dan Kelurahan Sepanjang Jaya, dan kami memilih pada Kelurahan Bojong Rawa Lumbu untuk dijadikan tempat KKN, kelurahan Bojong Rawalumbu dengan luas areal 581,92 $\mathrm{Ha}$ yang terdiri dari 640 RT dan 98 RW dengan wilayah sekolah SMK Widya Nusantara yang terletak di Jl. Tri Satya Perum Bumi Bekasi Baru No. 47 Rt. 001 Rw. 004, Desa Bojong Rawa lumbu, Kecamatan Rawa Lumbu (Yuda et al., 2020)

Di wilayah Sekolah SMK Widya Nusantara mempunyai visi dan misi, visi yaitu Terciptanya Insan yang mandiri, Berkarakter dilandasi Iman dan Taqwa, dan misi yaitu Menanamkan nilai-nilai Spiritual, Etika, Moral, dan Religius, Menanamkan sikap mandiri, Disiplin, Kreatif, Inovatif, produktif dan berani berkompetensi dengan penguasaal Life Skill, Mengembangkan Bakat, Minat, potensi dan prestasi dengan berorientasi Progam Ekstra Kurikuler, dan Mengembangkan potensi SDM melaui pelatihan - pelatihan dan Study lanjut untuk meningkatkan kompetensi dan Profesionalitas. Dengan tujuan yaitu menyiapkan peserta didik agar menjadi manusia produktif, mampu bekerja, mandiri, megisi lowongan pekerjaan yang ada di dunia usaha dan industri sebagai Tenaga kerja tingkat menengah sesuai dengan kompetensinya, menyiapkan peserta didik agar mampu memilih Karier, Ulet dan Gigih dalam Berkompetensi, beradaptasi di lingkungan kerja, dan membangun sifat Profesional sesuai dengan bidang keahlian yang di milikinya, membekali peseerta didik dengan ilmu pengetahuan, Teknologi dan Seni, agar mampu mengembangkan diri di kemudian hari baik secara mandiri maupun melalui jenjang pendidikan yang lebih tinggi (Harris, 2010).

Kuliah Kerja Nyata adalah bentuk kegiatan pengabdian kepada masyarakat oleh mahasiswa dengan pendekatan lintas keilmuan dan sektoral pada waktu dan daerah tertentu di Indonesia. Kegiatan KKN adalah cara untuk memberikan pengalaman belajar kepada Mahasiswa untuk hidup di tengah-tengah masyarakat di luar kampus dan secara langsung mengidentifikasi serta menangani masalah pembangunan yang dihadapi sebuah desa maupun sekolah.

Knowledge sharing bertujuan untuk menyebarkan ilmu atau informasi. Biasanya hal ini bisa berwujud dalam bentuk kegiatan, diskusi, presentasi, tutor, dan masih banyak lagi lainnya. Dengan implementasi yang tepat knowledge sharing bisa dilakukan dengan baik agar setiap orang tersebut bisa merasakan manfaatnya, saling berkembang dan belajar dari satu sama lain. Knowledge sharing yang bisa dilakukan dalam peningkatan potensi dan kompetensi siswa, bisa menggunakan berbagai cara lain, salah satunya adalah dengan membuat siswa lebih taat dalam hal peraturan disekolah (Cohon, 2010). 


\section{ANALISIS SITUASI}

Berikut analisis situasi yang menjadi focus dalam pelaksanaan pengabdian masyarakat :

a. Membantu merangkul kepada siswa/siswi untuk meningkatkan pengetahuan dan pembekalan di dalam dunia industri.

b. Memberikan pengetahuan dan meningkatkan kesadaran akan penting nya mengolah pola pikir dengan baik demi keberlangsungan hidup yang lebih baik.

c. Memberikan pengetahuan kepada siswa/siswi tentang teknik industri dan perminyakan.

d. Membantu tenaga pendidik yang bersangkutan untuk memberikan pengetahuan kepada siswa/siswi agar mampu mengembangkan kemampuan dalam bidang akademik maupun non akademik untuk membantu menangani pengolahan sampah dan meningkatkan kesadaran siswa akan lingkungan hidup yang bersih, s ehat dan rapi di Desa Bojong Rawa lumbu, Kecamatan Rawa Lumbu, di Wilayah Sekolah SMK Widya Nusantara.

\section{METODE PELAKSANAAN}

Metode kegiatan yang dilakukan adalah dengan metode luring atau terjun langsung kepada masyarakat dengan tetap mengikuti protokol kesehatan seperti memakai masker, menjaga jarak, dan selalu mencuci tangan/menggunakan hand sanitizer mengingat saat ini masih dalam situasi pandemi Covid-19. Kegiatan ini dilakukan oleh mahasiswi KKN mandiri reguler sebanyak 10 orang dari fakultas Teknik Program Studi Teknik Industri dan Teknik Perminyakan. Maka rincian metode pelaksanaan yang akan dilakukan yaitu:

a. Metodologi Survei Tempat

Digunakan untuk mengetahui permasalahan apa yang terjadi di daerah Desa Bojong Rawa lumbu, Kecamatan Rawa Lumbu di Wilayah Sekolah SMK Widya Nusantara.

b. Menentukan Tema Pengabdian Yang Akan Diberikan

Berdasarkan atas apa yang telah dilakukan dalam survei yang telah diuraikan pada latar belakang, maka tema KKN ini adalah Sharing Knowledge And Build A Better Mindset (Lancet, 2020).

c. Mencari Studi Pustaka

Studi pustaka adalah teknik pengumpulan data referensi dari berbagai jenis sumber keilmuan yang menunjang permasalahan yang sedang dicarikan solusinya, serta berbagai teori dan implementasi tentang tema KKN yang telah di pilih.

d. Membuat Materi Kegiatan

Berdasarkan studi pustaka yang telah dilakukan maka dibuatlah materi kegiatan, berupa penyuluhan (sosialisasi), seminar, dan pengajaran untuk siswa/siswi widya nusantara.

e. Menyajikan Penyuluhan, Seminar, dan Pengajaran

Penyuluhan, seminar, dan pengajaran diberikan dengan metode luring (offline / tatap muka) dengan materi yang berkaitan dengan program/kegiatan yang telah ditentukan.

f. Melakukan Kegiatan Monitoring dan Evaluasi

Monitoring dan evaluasi dilakukan untuk melihat sejauh mana perkembangan hasil dari pelaksanaan $\mathrm{KKN}$.

\section{HASIL DAN PEMBAHASAN}

Lokasi : JI. Tri Satya Perum Bumi Bekasi Baru No. 47 Rt. 001 Rw. 004, Desa Bojong Rawa lumbu, Kecamatan Rawa Lumbu, di Wilayah Sekolah SMK Widya Nusantara. 
Tabel 1. Kegiatan Pengadian Masyarakat

\begin{tabular}{|c|c|c|c|c|c|c|c|c|c|c|c|}
\hline \multirow{2}{*}{ No } & \multirow{2}{*}{$\begin{array}{c}\text { Nama } \\
\text { Kegiatan }\end{array}$} & \multicolumn{2}{|c|}{ Tujuan Kegiatan } & \multicolumn{2}{|c|}{$\begin{array}{l}\text { Ketepatan } \\
\text { Waktu } \\
\text { Pelaksanaan }\end{array}$} & \multirow{2}{*}{\begin{tabular}{|} 
Tingkat \\
Partisip \\
asi (\%)
\end{tabular}} & \multirow{2}{*}{$\begin{array}{c}\text { Faktor } \\
\text { Pendukung }\end{array}$} & \multirow{2}{*}{$\begin{array}{c}\text { Faktor } \\
\text { Penghambat }\end{array}$} & \multirow{2}{*}{ Jkem } & \multirow{2}{*}{ |Riil| } & \multirow{2}{*}{$\begin{array}{l}\text { Penanggung } \\
\text { Jawab }\end{array}$} \\
\hline & & \begin{tabular}{|l|} 
Target \\
\end{tabular} & Capain & $\begin{array}{c}\text { Rencan } \\
\text { a }\end{array}$ & $\begin{array}{c}\text { Realisa } \\
\text { si }\end{array}$ & & & & & & \\
\hline 1. & $\begin{array}{l}\text { Sosialisa } \\
\text { si } \\
\text { Pengeta } \\
\text { huan } \\
\text { Seputar } \\
\text { Teknik } \\
\text { Industri } \\
\text { dan } \\
\text { Teknik } \\
\text { Perminya } \\
\text { kan }\end{array}$ & $\begin{array}{l}\text { Sisw } \\
\text { a/sis } \\
\text { wi } \\
\text { dan } \\
\text { Maha } \\
\text { siswa }\end{array}$ & $\begin{array}{l}\text { Penget } \\
\text { ahuan } \\
\text { yang } \\
\text { menda } \\
\text { lam } \\
\text { tentan } \\
g \\
\text { seputa } \\
r \text { teknik }\end{array}$ & \begin{tabular}{|l|} 
Kam \\
is, \\
$18 /$ \\
$11 /$ \\
202 \\
1 \\
Pukul \\
08.00 \\
s/d \\
seles \\
ai. \\
\end{tabular} & \begin{tabular}{|l|} 
Kam \\
is, \\
$18 /$ \\
$11 /$ \\
202 \\
1 \\
Pukul \\
08.00 \\
s/d \\
10.00.
\end{tabular} & $\begin{array}{c}100 \\
\%\end{array}$ & $\begin{array}{l}\text { Siswa/siswi } \\
\text { antusias ikut } \\
\text { membantu } \\
\text { dalam } \\
\text { kegiatan ini. }\end{array}$ & - & \begin{tabular}{|l|}
120 \\
menit
\end{tabular} & & $\begin{array}{l}\text { Febri Firdaus } \\
\text { dan Farhan } \\
\text { Alfaridzi }\end{array}$ \\
\hline 2. & $\begin{array}{l}\text { Sosial } \\
\text { isasi } \\
\text { Pentin } \\
\text { gnya } \\
\text { Pener } \\
\text { apan } \\
\text { K3 }\end{array}$ & $\begin{array}{l}\text { Sisw } \\
\text { a/sis } \\
\text { wi } \\
\text { dan } \\
\text { Maha } \\
\text { siswa }\end{array}$ & $\begin{array}{l}\text { Penget } \\
\text { ahuan } \\
\text { yang } \\
\text { bermanf } \\
\text { aat } \\
\text { untuk } \\
\text { dunia } \\
\text { kerja }\end{array}$ & $\begin{array}{l}\text { Rab } \\
\text { u, } \\
17 / \\
11 / \\
202 \\
1 \\
\text { Pukul } \\
08.00 \\
\text { s/d } \\
\text { seles } \\
\text { ai. }\end{array}$ & $\begin{array}{l}\text { Rab } \\
\text { u, } \\
17 / \\
11 / \\
202 \\
1 \\
\text { Pukul } \\
08.00 \\
\text { s/d } \\
10.00\end{array}$ & $\begin{array}{c}100 \\
\%\end{array}$ & \begin{tabular}{|c|} 
Siswa/siswi \\
antusias ikut \\
membantu \\
dalam \\
kegiatan ini.
\end{tabular} & - & \begin{tabular}{|l|}
120 \\
menit
\end{tabular} & & $\begin{array}{l}\text { Reza Maulana } \\
\text { dan Miftahul } \\
\text { Fattah A }\end{array}$ \\
\hline 3. & $\begin{array}{l}\text { Penyu } \\
\text { luhan } \\
\text { Memb } \\
\text { angun } \\
\text { Pola } \\
\text { Pikir } \\
\text { yang } \\
\text { Lebih } \\
\text { Baik. }\end{array}$ & $\begin{array}{l}\text { Sisw } \\
\text { a/sis } \\
\text { wi, } \\
\text { Guru } \\
\text { dan } \\
\text { Maha } \\
\text { siswa }\end{array}$ & $\begin{array}{l}\text { Mening } \\
\text { katkan } \\
\text { Pola } \\
\text { Pikir } \\
\text { yang } \\
\\
\text { Jauh } \\
\text { Lebih } \\
\text { Baik }\end{array}$ & $\begin{array}{l}\text { Sela } \\
\text { sa, } \\
16 / \\
11 / \\
202 \\
1 \\
\text { Puk } \\
\text { ul } \\
08.0 \\
0 \text { s/d } \\
\text { sele } \\
\text { sai. }\end{array}$ & $\begin{array}{l}\text { Sela } \\
\text { sa, } \\
16 / \\
11 / \\
202 \\
1 \\
\text { Puk } \\
\text { ul } \\
08.0 \\
0 \text { s/d } \\
10.0 \\
0 .\end{array}$ & $\begin{array}{c}100 \\
\%\end{array}$ & \begin{tabular}{|l} 
Siswa/siswi \\
beserta guru \\
- guru \\
antusias ikut \\
membantu \\
$\quad$ dalam \\
kegiatan \\
ini.
\end{tabular} & - & \begin{tabular}{|l|}
120 \\
menit
\end{tabular} & & $\begin{array}{l}\text { Gilang Purbo } \\
\text { A } \\
\text { dan Anggit } \\
\text { Dzuhri A }\end{array}$ \\
\hline 4. & $\begin{array}{l}\text { Peng } \\
\text { enala } \\
\mathrm{n} \text { dan } \\
\text { Meng } \\
\text { adaka } \\
\mathrm{n} \\
\text { Sena } \\
\mathrm{m} \\
\text { Pagi } \\
\text { Bersa } \\
\text { ma }\end{array}$ & $\begin{array}{l}\text { Sisw } \\
\text { a/sis } \\
\text { wi, } \\
\text { Guru } \\
\text { dan } \\
\text { Maha } \\
\text { siswa }\end{array}$ & $\begin{array}{l}\text { Tubuh } \\
\text { menja } \\
\text { di } \\
\text { sehat } \\
\text { dan } \\
\text { oleh } \\
\text { penyaki } \\
\text { t covid- } \\
19\end{array}$ & $\begin{array}{l}\text { Seni } \\
\mathrm{n}, \\
15 / \\
11 / \\
202 \\
1 \\
\text { Pukul } \\
08.0 \\
0 \mathrm{~s} / \mathrm{d} \\
\text { sele } \\
\text { sai. }\end{array}$ & $\begin{array}{l}\text { Seni } \\
\mathrm{n}, \\
15 / \\
11 / \\
202 \\
1 \\
\text { Pukul } \\
08.0 \\
0 \mathrm{~s} / \mathrm{d} \\
09.0 \\
0\end{array}$ & $\begin{array}{c}100 \\
\%\end{array}$ & \begin{tabular}{|c|} 
Siswa/siswi \\
antusias ikut \\
membantu \\
dalam \\
kegiatan ini.
\end{tabular} & $\begin{array}{c}\text { Siswa/siswiS } \\
\text { ulit diatur }\end{array}$ & \begin{tabular}{|c|}
60 \\
menit
\end{tabular} & & $\begin{array}{l}\text { Naufal } \\
\text { Erdiyansyah } \\
\text { dan Aminudin } \\
\text { Musanif M }\end{array}$ \\
\hline 5. & $\begin{array}{l}\text { Peng } \\
\text { ajaran } \\
\text { Pada } \\
\text { Siswa } \\
\text { /Siswi } \\
\text { SMK } \\
\text { Widya } \\
\text { Nusa } \\
\text { ntara }\end{array}$ & $\begin{array}{l}\text { Sisw } \\
\text { a/sis } \\
\text { wi } \\
\text { dan } \\
\text { Maha } \\
\text { siswa }\end{array}$ & $\begin{array}{l}\text { Ilmu } \\
\text { Penge } \\
\text { tahua } \\
\mathrm{n} \text { yang } \\
\text { berma } \\
\text { nfaat } \\
\text { yang } \\
\text { didapa } \\
\mathrm{t} \\
\text { dari } \\
\text { Mahas } \\
\text { iswa }\end{array}$ & $\begin{array}{l}\text { Jum' } \\
\text { at, } \\
19 / \\
11 / \\
202 \\
1 \\
\text { Pukul } \\
07.0 \\
0 \text { s/d } \\
\text { sele } \\
\text { sai. }\end{array}$ & $\begin{array}{l}\text { Jum' } \\
\text { at, } \\
19 / \\
11 / \\
202 \\
1 \\
\text { Pukul } \\
07.0 \\
0 \text { s/d } \\
10.0 \\
0\end{array}$ & $\begin{array}{c}100 \\
\%\end{array}$ & $\begin{array}{l}\text { Siswa/siswi } \\
\text { antusias ikut } \\
\text { membantu } \\
\text { dalam } \\
\text { kegiatan ini. }\end{array}$ & - & $\begin{array}{l}180 \\
\text { men } \\
\text { it }\end{array}$ & & $\begin{array}{l}\text { Shaharani Tri } \\
\text { Maulina dan } \\
\text { Hanah } \\
\text { Luptiyah }\end{array}$ \\
\hline
\end{tabular}


Salah satu program rencana tindak lanjut yang kelompok kami usulkan yaitu :

a. Mengadakan Senam Pagi Bersama

Tujuan dari kegiatan ini yaitu agar siwa/siswi serta guru - guru bisa mengetahui pentingnya menjaga imun tubuh yang sehat serta dapat dijauhkan oleh serangan penyakit covid-19 untuk lingkungan sekolah SMK Widya Nusantara yakni membuat lingkungan sekolah menjadi lebih aman dari penyakit covid-19 dan tubuh menjadi sehat jasmani \& rohani untuk para siswa/siswi serta guru - gurunya. Selain itu, bisa meningkatkan imun tubuh yang baik untuk kesehatan tubuh.

b. Membangun Pola Pikir yang Lebih Baik

Tujuan dari kegiatan ini yaitu agar pola pikir siswa/siswi SMK Widya Nusantara menjadi jauh lebih baik untuk kedepannya dan meningkatkan ilmu pengetahuan dalam bersosialisasi dimana pun dan kapan pun, serta perlu adanya dukungan maupun dorongan antara guru dan orangtua untuk tetap mendidik, menasihati dan memotivasi agar bisa pola pikirnya menjadi lebih jauh terutama setelah lulus dari sekolah SMK Widya Nusantara (Gendler, 2000).

\section{KESIMPULAN DAN REKOMENDASI}

KKN atau Kuliah Kerja Nyata adalah salah satu bentuk pengabdian dari mahasiswa untuk masyarakat. KKN Mandiri Reguler Fakultas Teknik Edisi IV Kelompok 18 dikelas 1A2 jurusan Teknik Industri Fakultas Teknik ini melakukan pengabdian di wilayah Sekolah SMK Widya Nusantara di Jl. Tri Satya Perum Bumi Bekasi Baru No. 47 Rt. 001 Rw. 004, Desa Bojong Rawa lumbu, Kecamatan Rawa Lumbu. Kegiatan KKN ini dimulai pada hari Senin, 15 November 2021 dan berakhir pada hari Jum'at, 19 November 2021.

Keadaan wilayah Sekolah SMK Widya Nusantara di JI. Tri Satya Perum Bumi Bekasi Baru No. 47 Rt. 001 Rw. 004, Desa Bojong Rawa lumbu, Kecamatan Rawa Lumbu. ini termasuk kedalam wilayah sekolah yang kurang dalam pengetahan bersosialisasi kepada siswa/siswi SMK Widya Nusantara. Maka mahasiswa KKN Universitas Bhayangkara Jakarta Raya yang melakukan kegiatan KKN di wilayah Sekolah SMK Widya Nusantara di Jl. Tri Satya Perum Bumi Bekasi Baru No. 47 Rt. 001 Rw. 004, Desa Bojong Rawa lumbu, Kecamatan Rawa Lumbu, diharapkan bisa membantu meningkatkkan pengetahuan dalam bersosialisasi serta meningkatkan pola pikir kepada siswa/siswi SMK Widya Nusantara dan dapat melaksanakan program kerja dengan baik sesuai dengan yang diharapan.

Dari pemaparan program yang ada pada bab sebelumnya maka dapat disimpulkan bahwa Program KKN Mandiri Reguler Fakultas Teknik Edisi IV kelompok 18 kelas 1A2 jurusan Teknik Industri Fakultas Teknik di wilayah Sekolah SMK Widya Nusantara di Jl. Tri Satya Perum Bumi Bekasi Baru No. 47 Rt. 001 Rw. 004, Desa Bojong Rawa lumbu, Kecamatan Rawa Lumbu, yang telah dijalankan antar lain meliputi program pengenalan dan mengadakan senam pagi, bersosialisasi pengetahuan seputar teknik industri dan teknik perminyakan, bersosialisasi pentingnya penerapan $\mathrm{K} 3$, penyuluhan membangun pola pikit yang lebih baik, dan Pengajaran pada siswa/siswi SMK Widya Nusantara.

Bagi siswa/siswi SMK Widya Nusantara yang masih kurang dalam meningkatkan pengetahan bersosialisasi serta meningkatkan pola pikir yang jauh lebih baik dan dibutuhkan pula kerjasama antara pihak sekolah seperti guru - guru dan orangtua untuk tetap mendidik, menasihati, dan memotivasi kepada siswa/siswi SMK Widya Nusantara agar bisa meningkatkan pola pikirnya yang jauh lebih baik dan meningkatkan pengetahuan bersosialisasi.

Demikian laporan KKN Mandiri Reguler Fakultas Teknik Edisi IV ini kami buat, semoga dapat bermanfaat bagi pihak-pihak yang membutuhkan. Kami mengucapkan terima kasih kepada seluruh pihak yang telah membantu dalam pelaksanaan program KKN Mandiri Reguler Fakultas Teknik Edisi IV Universitas Bhayangkara Jakarta Raya.

Copyright @ 2021 Jurnal JSTPM 2 (2) : 143-148 (Desember 2021) 


\section{DAFTAR PUSTAKA}

Cohon, R. (2010). Hume's Moral Philosophy. In The Stanford Encyclopedia of Philosophy, Fall 2010, edited by Edward N. Zalta, http://plato.stanford.edu/archives/fall2010/ventries/hume-moral.

Gendler, T. S. (2000). The Puzzle of Imaginative Resistance. Journal of Philosophy, 97(2), 55-81.

Harris, J. A. (2010). Reid on Hume on Justice. London: Palgrave: In Reid on Ethics, edited by Sabine Roeser.

Lancet, T. (2020). COVID-19: Fighting Panic with Information. International Seminar of Information Technology, 2020 / 02, 395(10224).

Yuda, Komara, T., Damanik, Janianton, \& Nurhadi. (2020). Examining Emerging Social Policy during COVID-19 in Indonesia and the Case for a Community-based Support System. Asia Pacific Journal of Social Work and Development, http://doi.org/10.1080/02185385. 